\title{
Prevention of High-Dose Cytosine Arabinoside-Induced Acute Pericarditis with Preemptive Dexamethasone Administration: A Case Report and Literature Review
}

\author{
Weerapat Owattanapanich (iD) and Theera Ruchutrakool $(\mathbb{D}$ \\ Division of Hematology, Department of Medicine, Faculty of Medicine, Siriraj Hospital, Mahidol University, Bangkok, Thailand \\ Correspondence should be addressed to Theera Ruchutrakool; sitrc@mahidol.ac.th
}

Received 20 November 2017; Revised 28 December 2017; Accepted 17 January 2018; Published 11 February 2018

Academic Editor: Chihaya Imai

Copyright (c) 2018 Weerapat Owattanapanich and Theera Ruchutrakool. This is an open access article distributed under the Creative Commons Attribution License, which permits unrestricted use, distribution, and reproduction in any medium, provided the original work is properly cited.

Pericarditis/pericardial effusion (PC/PEEF) is a rare but fatal complication of cytosine arabinoside (Ara-C). We report an acute myeloid leukemia (AML) patient who developed massive pericardial effusion after a second Ara-C exposure. As Ara-C was most beneficial in controlling the leukemia, she was treated with a further cycle of Ara-C along with dexamethasone to prevent the complication from reoccurring. No PC/PEEF was subsequently detected.

\section{Introduction}

AML is the most common acute leukemia in adults. Its annual incidence in Thailand is 1.4 per 100,000 population, with 5 -year disease-free survival and overall-survival rates of $41.0 \%$ and $22.2 \%$, respectively [1]. The most efficient chemotherapeutic agents are anthracyclin and Ara-C. Ara-C is administered as a standard dose during induction and a high dose during consolidation. Besides bone marrow suppression, nausea, vomiting, fatigue, and mouth sores, the side effects of high-dose Ara-C (HIDAC) include conjunctivitis and cerebellar toxicity. PC/PEEF, a rare but often lethal complication of standard and high-dose Ara-C, was first reported in 1984 [2]. No management guidelines exist for $\mathrm{PC} / \mathrm{PEEF}$. Based on a literature review and our experience with an AML patient with this rare complication after Ara-C treatment, we propose a strategy to manage it and rechallenge with Ara-C without the complication.

\section{Case Report}

A 38-year-old female presented with fatigue for 2 months. On examination, pale skin and petechiae along both legs were observed; others were unremarkable. The initial blood count showed a hemoglobin of $7.8 \mathrm{~g} / \mathrm{dL}$, WBC of $242.7 \times 10^{9} / \mathrm{L}$ (myeloblasts and monoblasts constituted over 90\%), and platelet count of $21 \times 10^{9} / \mathrm{L}$. By flow cytometry, the malignant cells (86\%) were positive for CD13, CD33, CD11b, CD11c, CD14, CD64, CD117, and MPO which were compatible with AML-M4 according to FAB classification. By G-banding karyotyping, no abnormalities were observed. After establishing the diagnosis of AML, the patient received standard remission induction therapy with Ara-C $\left(100 \mathrm{mg} / \mathrm{M}^{2} /\right.$ day; 12 -hour continuous infusion once daily for 7 consecutive days) and idarubicin $\left(12 \mathrm{mg} / \mathrm{M}^{2} /\right.$ day; intravenous infusion for 3 consecutive days). She regenerated at day 24 and entered complete remission without grade 4 complications except cytopenia. It was planned that she would receive allogeneic stem cell transplantation. While awaiting approval of this treatment from her covered medical expenses, we decided to control her disease with consolidation therapy, HIDAC regimen for 3 cycles.

A week after complete remission, Ara-C $\left(1,000 \mathrm{mg} / \mathrm{M}^{2} /\right.$ day; 2-hour continuous infusion every 12 hours for 6 doses) commenced. On day 3 of this regimen, during administration of the fourth Ara-C dose, she complained of a sudden onset of dyspnea and sharp, persistent pain in the substernal and epigastric areas. She had no fever, sweating, cough, or palpitation. Her temperature was $36.8^{\circ} \mathrm{C}$ and pulse rate was 


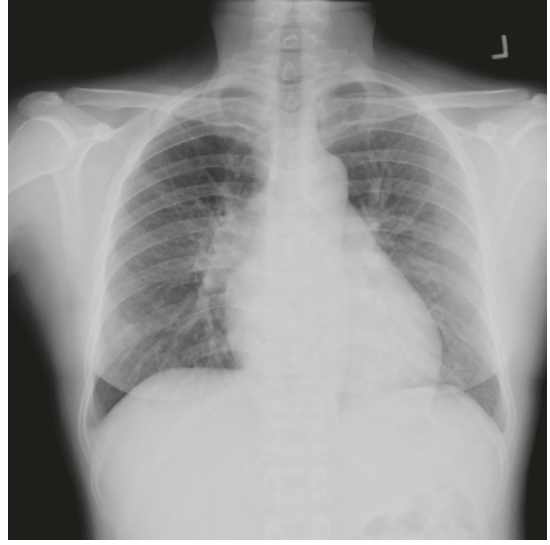

(a)

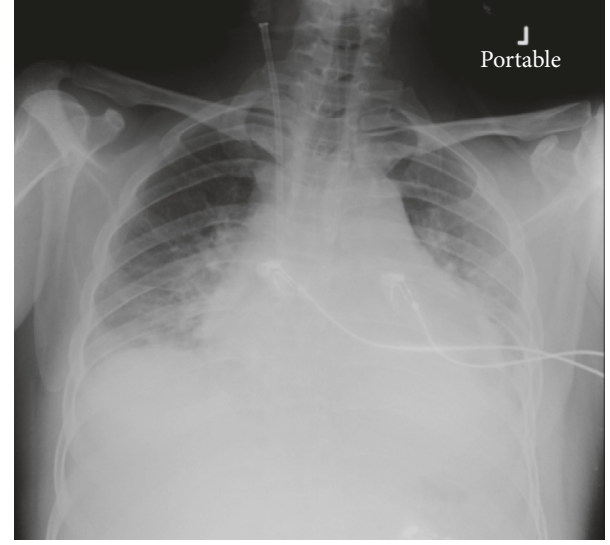

(b)

Figure 1: Chest X-rays: (a) prior to cytosine arabinoside; (b) day 3 of the first cycle of HIDAC.

80/min and regular, but her blood pressure, measured repeatedly at all extremities, was $80 / 40 \mathrm{mmHg}$. A chest X-ray revealed massive cardiomegaly (Figure $1(\mathrm{~b})$ ) relative to the baseline cardiac size on the admission day (Figure 1(a)). Electrocardiography showed normal sinus rhythm and no low voltage, electrical alternans, or ST-T abnormality.

An echocardiography disclosed massive PEEF without cardiac tamponade. The left ventricular ejection fraction was $71 \%$ without either an abnormal wall motion or significant valve dysfunction. Computed tomography of the chest and abdomen was unremarkable except revealing massive PEEF. Troponin-T was under $0.003 \mathrm{ng} / \mathrm{mL}(<0.01 \mathrm{ng} / \mathrm{mL})$, and CK-MB was $0.67 \mathrm{IU} / \mathrm{L}$ (5-25 IU/L). Viral serologic studies (herpes simplex virus, cytomegalovirus, Epstein-Barr virus, and hepatitis B virus) detected by $\operatorname{IgM}$ and IgG were all negative. Antinuclear antibody was also negative.

Given no other apparent causes of PC/PEEF, Ara-Cinduced PC/PEEF was highly suspected. After $2,000 \mathrm{~mL}$ of normal saline infusion within 15 minutes, hypotension was unimproved. The initial central venous pressure revealed $24 \mathrm{~cm} \mathrm{H}_{2} \mathrm{O}$. Dopamine $(10 \mu \mathrm{g} / \mathrm{kg} /$ minute $)$ was started. Besides ceasing Ara-C, $10 \mathrm{mg} /$ day of intravenous dexamethasone was initiated. The substernal and epigastric pain subsequently disappeared within six hours, with BP stabilized at $110 / 80 \mathrm{mmHg}$. The inotropic drug was discontinued within 26 hours. The cardiac shadow was markedly decreased three days after commencement of the dexamethasone treatment. At day 7, an echocardiography revealed only small pericardial effusion, so a planned pericardiocentesis was canceled. The dexamethasone was tapered and stopped by day 11 . She was discharged on day 23, still without evidence of effusion.

As Ara-C was deemed essential for the AML treatment, it was decided to repeat the HIDAC consolidation therapy but with preemptive, high-dose dexamethasone. Ten $\mathrm{mg} /$ day intravenous dexamethasone was therefore initiated the day before cytoreduction and continued for 6 days of each cycle. The HIDAC regimen administration went without complications. The patient successfully underwent a matched-sibling stem cell transplantation in July 2012. As of January 2017, she remains in remission.

\section{Discussion}

PC/PEEF is an uncommon, but potentially fatal, AML complication. Its pathogenesis is multifactorial, possibly resulting from the underlying disease, the concomitant infection, accompanying bleeding complications arising from thrombocytopenia or DIC, the chemotherapy, or radiation. Thus, Ara-C-induced PC/PEEF should always be an exclusion diagnosis. In our case, we excluded both virological and autoimmune pathogenesis. Despite the lack of cytology of the pericardial effusion, we deemed that leukemic involvement and hemorrhagic complications in this patient, who was in remission and without any complaints, could be ruled out. Thus, this severe episode should be described to the cytoreductive regimen. Chemotherapeutic agents which have been reported to induce PC/PEEF include daunorubicin, doxorubicin, cyclophosphamide, bleomycin, and actinomycin D. Our patient received anthracycline six weeks before the development of PC/PEEF; the longest duration of anthracycline-induced PC/PEEF onset ever reported was 29 days. Therefore, Ara-C is the most likely cause of PC/PEEF in our patient, rather than doxorubicin.

Ara-C-induced PC/PEEF was first described by Vaickus in 1984 [2]; a literature review revealed that only 10 patients (including our patient) have been reported. Interestingly, two patients developed two episodes of this complication $[3,4]$. The pathogenesis of these severe complications is unclear, but type IV delayed hypersensitivity [4-9], anaphylaxis [10], and direct toxicity to the endothelium [11] have been suggested.

Table 1 tabulates previously published series of PC/PEEF. The onset of PC/PEEF varied between 2 and 29 days (median: 3 days) after receiving repeated doses of Ara-C. Most patients received the HIDAC regimen. Our patient developed PC/PEEF three days after HIDAC; we hypothesize that there was a type IV delayed hypersensitivity, compatible with such reactions developing within 10 days of the last exposure. To prove this, a cardiac muscle biopsy showing infiltration of T-lymphocytes would be required. 
TABLe 1: Reported cases of Ara-C-induced pericarditis/pericardial effusion.

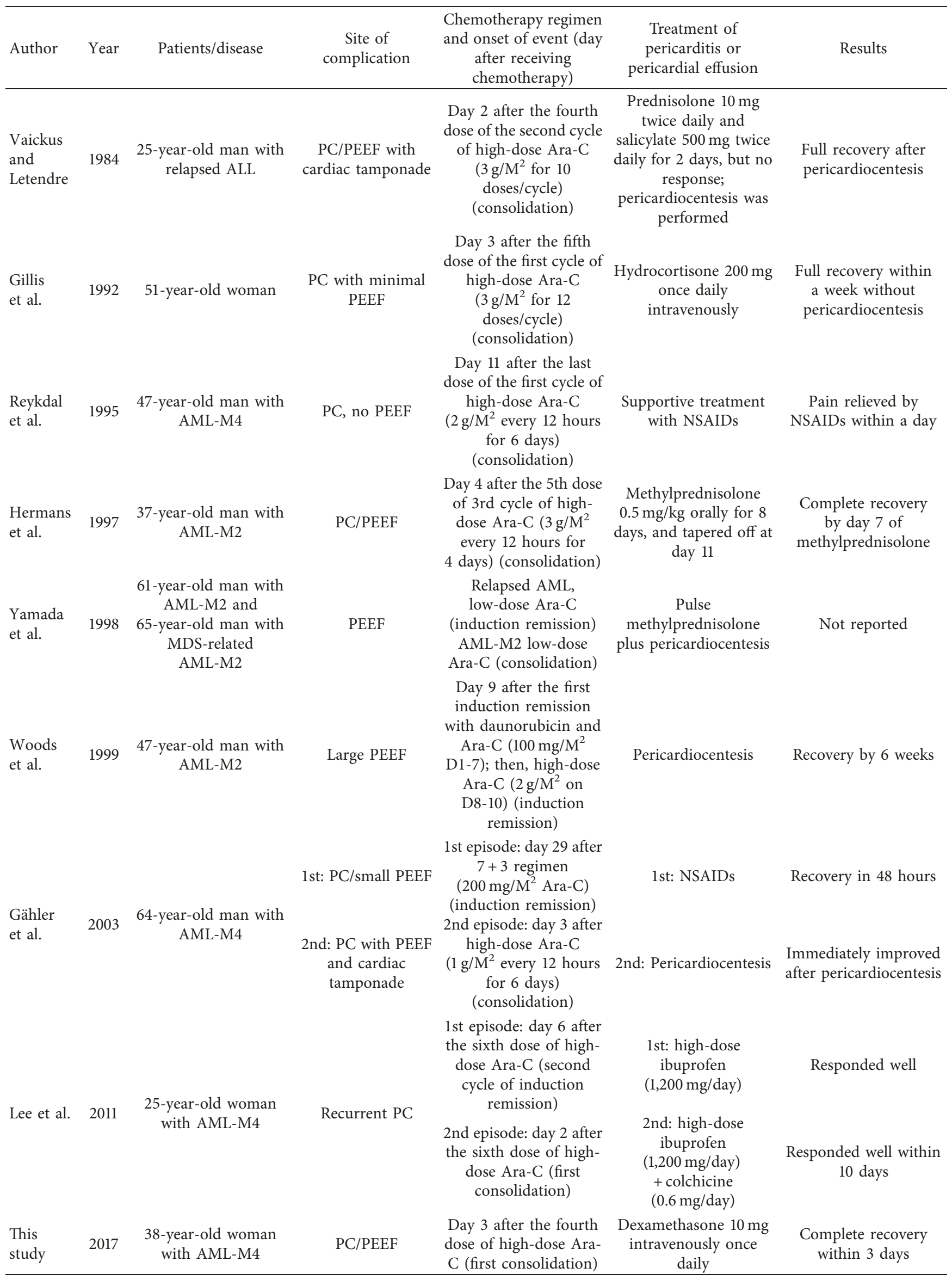


These considerations leave us with the question of how to treat PC/PEEF, either prophylactically or upon occurrence. PEEF management depends on the degree of cardiac tamponade; if clinical cardiac tamponade is detected, pericardiocentesis is the treatment of choice. Systemic corticosteroids were first introduced in treating this complication in 1984 [2] with the hypothesis of a delayed hypersensitivity or anaphylaxis, but the response was undesirable. This could be due to an insufficient amount of steroid being used (prednisolone $20 \mathrm{mg}$ /day). Subsequently, Gillis introduced higher dose of steroid (hydrocortisone $200 \mathrm{mg} /$ day), and the results were promising [5], similar to our patient. Successful results with various types and dosage of corticosteroids, such as intravenous hydrocortisone (200 mg/day) and oral methylprednisolone ( $0.5 \mathrm{mg} / \mathrm{kg} /$ day $)$, have been reported [6-8]. Furthermore, we insisted on using the HIDAC regimen for the second course of consolidation chemotherapy with prophylactic dexamethasone. As PC/PEEF did not reappear, we suggest that patients with Ara-C-induced $\mathrm{PC} / \mathrm{PEEF}$ may be treated with the same regimen combined with a systemic high-dose corticosteroid. From our experience, the optimal dexamethasone dosage to prevent this complication is at least $8-10 \mathrm{mg} /$ day, which is equivalent to hydrocortisone dose of $200-250 \mathrm{mg} /$ day or prednisolone dose of $40-50 \mathrm{mg} /$ day.

\section{Conflicts of Interest}

The authors have no conflicts of interest regarding the publication of this manuscript.

\section{Acknowledgments}

The authors would like to thank Professor Peter Hokland for his comments and wonderful suggestions about this manuscript.

\section{References}

[1] P. Niparuck, S. Chuncharunee, A. Ungkanont et al., "Longterm outcomes of de novo acute myeloid leukemia in Thai patients," Journal of the Medical Association of Thailand, vol. 92, no. 9, pp. 1143-1149, 2009.

[2] L. Vaickus and L. Letendre, "Pericarditis induced by high-dose cytarabine therapy," Archives of Internal Medicine, vol. 144, no. 9, pp. 1868-1869, 1984.

[3] A. Gähler, F. Hitz, U. Hess, and T. Cerny, "Acute pericarditis and pleural effusion complicating cytarabine chemotherapy," Oncology Research and Treatment, vol. 26, no. 4, pp. 348-350, 2003.

[4] G. Y. Lee, K. T. Ahn, C. W. Jung et al., "Recurrent pericarditis after chemotherapy for acute myeloid leukemia: a case report and a modern approach to chemotherapy-induced pericarditis," Cardiology, vol. 120, no. 3, pp. 130-134, 2011.

[5] S. Gillis, E. J. Dann, Y. Ilan et al., "Pericarditis associated with high-dose cytarabine therapy for acute myeloblasts leukemia: a rare complication of therapy," Leukemia \& Lymphoma, vol. 6, no. 6, pp. 525-526, 1992.

[6] S. Reykdal, R. Sham, and P. Kouides, "Cytarabine-induced pericarditis: a case report and review of the literature of the cardio-pulmonary complications of cytarabine therapy," Leukemia Research, vol. 19, no. 2, pp. 141-144, 1995.

[7] C. Hermans, N. Straetmans, J. L. Michaux et al., "Pericarditis induced by high-dose cytosine arabinoside chemotherapy," Annals of Hematology, vol. 75, no. 1-2, pp. 55-57, 1997.

[8] T. Yamada, H. Tsurumi, T. Hara, M. Sawada, M. Oyama, and H. Moriwaki, "Cytarabine-induced pericarditis," Rinsho Ketsueki, vol. 39, no. 11, pp. 1115-1120, 1998.

[9] T. Woods, B. Vidarsson, D. Mosher et al., "Transient effusiveconstrictive pericarditis due to chemotherapy," Clinical Cardiology, vol. 22, no. 4, pp. 316-318, 1999.

[10] B. L. Powell, P. J. Zekan, H. B. Muss et al., "Ara-C syndrome during low-dose continuous infusion therapy," Medical and Pediatric Oncology, vol. 14, no. 6, pp. 310-312, 1986.

[11] M. A. Boogaerts, S. Malbrain, and R. L. Verwilghen, "The Ara-C syndrome: direct endothelial cytotoxicity," British Journal of Haematology, vol. 66, p. 423, 1987. 


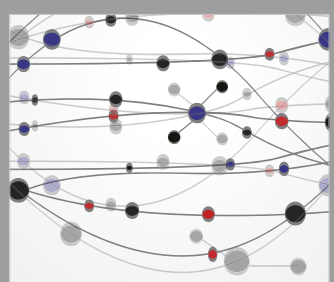

The Scientific World Journal
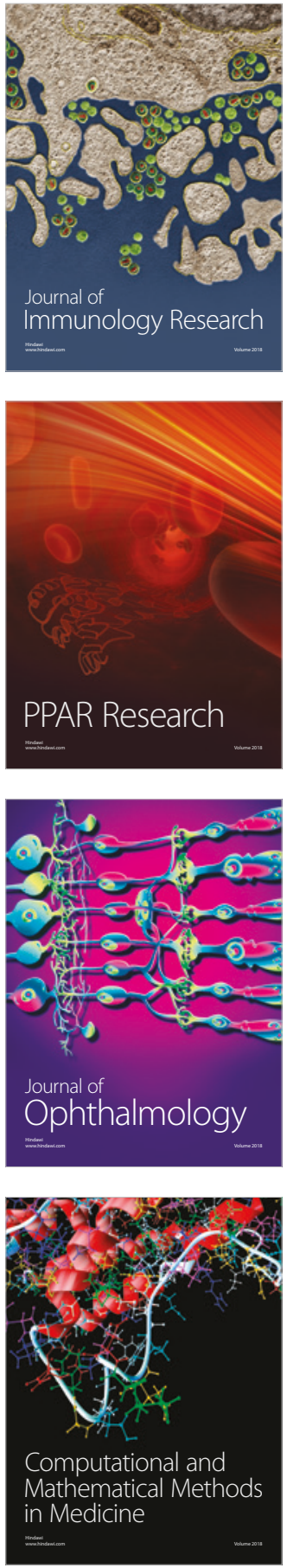

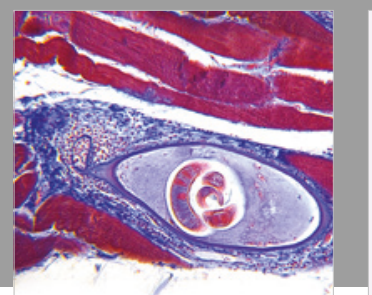

Gastroenterology Research and Practice

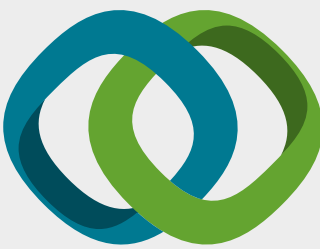

\section{Hindawi}

Submit your manuscripts at

www.hindawi.com
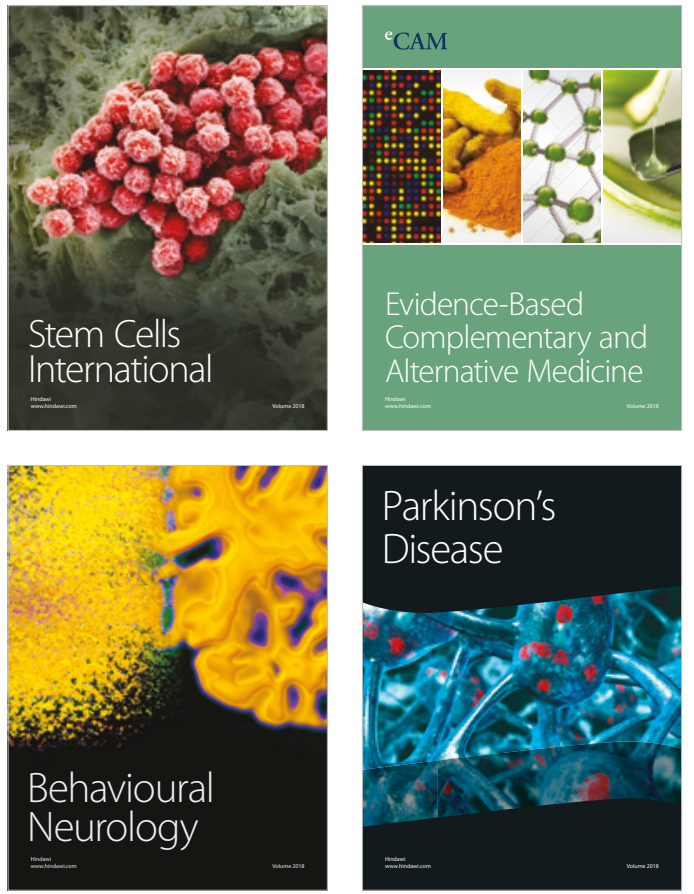

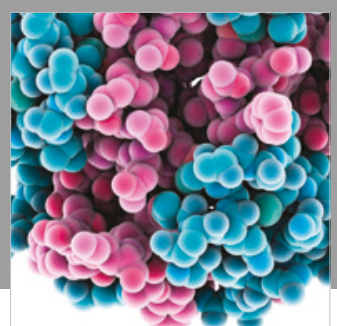

ournal of

Diabetes Research

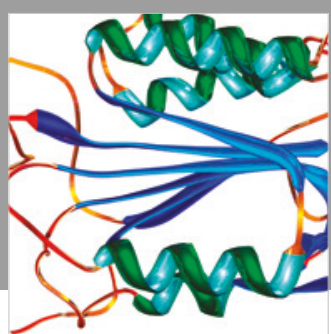

Disease Markers
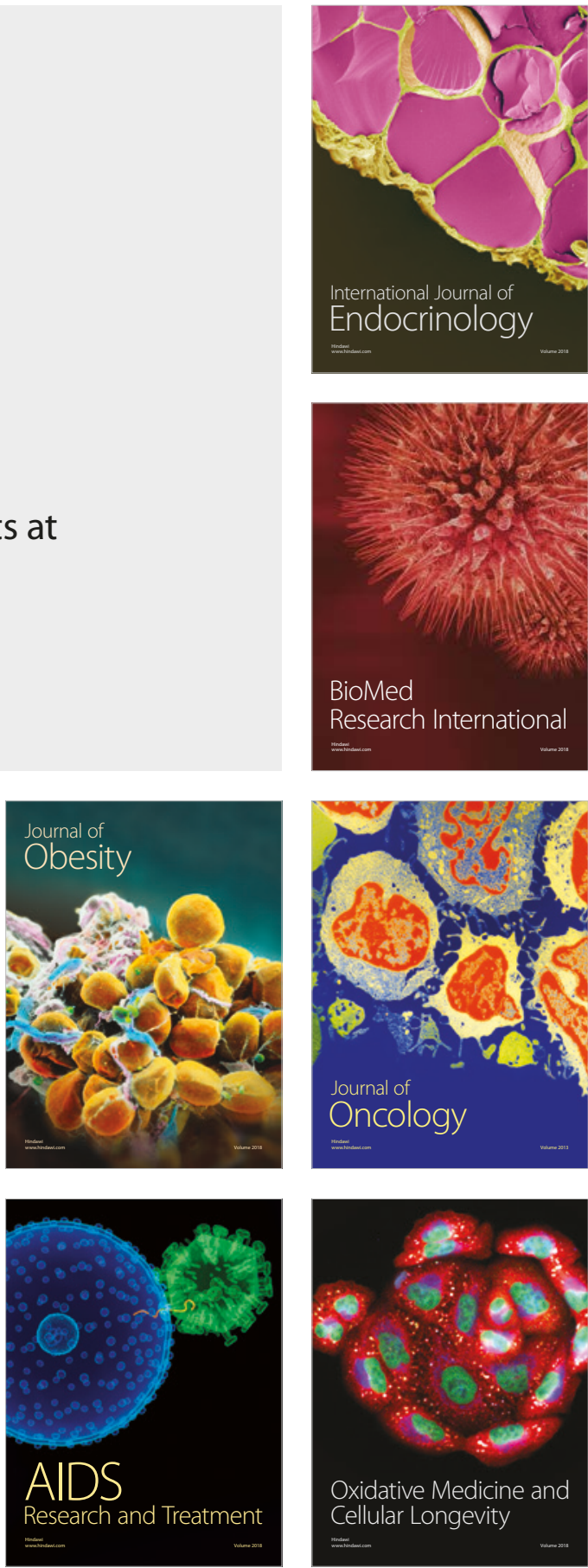